OPEN ACCESS

Edited by:

José Castro-Sotomayor, California State University, Channel Islands, United States

Reviewed by: Wilhelm Peekhaus, University of Wisconsin-Milwaukee, United States Kate Maddalena, University of Toronto Mississauga,

Canada

*Correspondence:

George L.W. Perry

george.perry@auckland.ac.nz

Specialty section: This article was submitted to

Science and

Environmental Communication,

a section of the journa

Frontiers in Environmental Science

Received: 22 October 2020

Accepted: 30 April 2021

Published: 04 June 2021

Citation:

Perry GLW, Richardson SJ, Harré N, Hodges D, Lyver PO'B, Maseyk FJF,

Taylor $R$, Todd $\mathrm{JH}$, Tylianakis $\mathrm{JM}$,

Yletyinen J and Brower A (2021)

Evaluating the Role of Social Norms in

Fostering Pro-

Environmental Behaviors.

Front. Environ. Sci. 9:620125.

doi: 10.3389/fenvs.2021.620125

\section{Evaluating the Role of Social Norms in Fostering Pro-Environmental Behaviors}

George L.W. Perry ${ }^{1 *}$, Sarah J. Richardson ${ }^{2}$, Niki Harré $^{3}$, Dave Hodges $^{4}$, Phil O’B. Lyver ${ }^{2}$, Fleur J.F. Maseyk ${ }^{5}$, Riki Taylor ${ }^{1}$, Jacqui H. Todd ${ }^{6}$, Jason M. Tylianakis ${ }^{7}$, Johanna Yletyinen ${ }^{2,7}$ and Ann Brower ${ }^{8}$

${ }^{1}$ School of Environment, University of Auckland, Auckland, New Zealand, ${ }^{2}$ Manaaki Whenua-Landcare Research, Lincoln, New Zealand, ${ }^{3}$ School of Psychology, University of Auckland, Auckland, New Zealand, ${ }^{4}$ DairyNZ, Hamilton, New Zealand, ${ }^{5}$ The Catalyst Group, Wellington, New Zealand, ${ }^{6}$ The New Zealand Institute for Plant and Food Research Limited, Auckland, New Zealand, ${ }^{7}$ School of Biological Sciences, University of Canterbury, Christchurch, New Zealand, ${ }^{8}$ School of Earth and Environment, University of Canterbury, Christchurch, New Zealand

Human activity is changing the biosphere in unprecedented ways, and addressing this challenge will require changes in individual and community patterns of behavior. One approach to managing individual behaviors is "top-down" and involves imposing sanctions through legislative frameworks. However, of itself, a top-down framework does not appear sufficient to encourage the changes required to meet environmental sustainability targets. Thus, there has been interest in changing individual-level behavior from the "bottom-up" by, for example, fostering desirable proenvironmental behaviors via social norms. Social norms arise from expectations about how others will behave and the consequences of conforming to or departing from them. Meta-analyses suggest that social norms can promote pro-environmental behavior. Environmental social norms that appear to have changed in recent decades and have themselves promoted change include recycling, include nascent behavioral shifts such as the move away from single-use plastics and flight shaming (flygskam). However, whether the conditions under which pro-environmental social norms emerge and are adhered to align with environmental systems' features is unclear. Furthermore, individuals might feel powerless in a global system, which can limit the growth and influence of pro-environmental norms. We review the conditions believed to promote the development of and adherence to social norms, then consider how those conditions relate to the environmental challenges of the Anthropocene. While promoting social norms has a valuable role in promoting pro-environmental actions, we conclude that norms are most likely to be effective where individual actions are immediately evident and have an obvious and local effect.

Keywords: pro-environmental behavior, social norms, uncertainty, collective action, psychological distance 
“The ongoing process of environmental degradation is thus deeply rooted in multiple large-scale collective action dilemmas, in which individual rationality is pitted against collective goods on regional, national or even global scales.” Duit (2010, p. 900).

\section{INTRODUCTION}

Environmental degradation and biodiversity loss are among the most urgent challenges facing humanity (Ripple et al., 2017; Díaz et al., 2019). Business as usual offers little hope of meeting environmental policy targets. Scientists are urged to contribute solutions matching the complexity of the social-ecological issues in question (Rands et al., 2010; Cook et al., 2013) and to move beyond the "loading dock approach" of delivering science to the public and hoping it will be used (Enquist et al., 2017). Integrating social and environmental sciences is essential if biophysical evidence is to be used to inform the development of pro-environmental behaviors by society, industry and government; however, the scales and contexts in which different pro-environmental behaviors will work are unresolved (Ostrom, 2000; Oullier, 2013). Solving environmental problems often requires individuals to cooperate for a common good or goal. These actions, however, sit alongside individual-level conflicts with the group outcome and concerns of inequality where there are benefits for free-riders (Hardin, 1968; Duit, 2010), or disparities across individuals (or sub-groups) in the costs of taking the same action. Importantly too, people bring their membership of social groups to collective problems, which may include a history of conflict that can reduce people's willingness to work toward a common goal (Bernhard et al., 2006).

Recent high-profile publications (Nyborg et al., 2016; Bodin, 2017; Byerly et al., 2018; Centola et al., 2018; Otto et al., 2020) have explored how fostering social norms may initiate and maintain desirable environmental behaviors. Here, we consider the extent to which social norms can contribute to solving large-scale ecological problems. We briefly review the properties of social norms and the conditions under which they are generated and maintained. Then, we summarize how the properties of environmental systems challenge the establishment of pro-environmental social norms. A vast literature exists on achieving behavioral change-social psychology, cognitive science, behavioral economics, regulatory research, and law to name a few. We do not aim to extensively review this material (for reviews see Gifford, 2011; Young, 2015; Fehr and Schurtenberger, 2018; Nyborg, 2018). Instead, drawing on the literature, we highlight potential misalignments between norm-fostering conditions and environmental systems, while outlining the contexts where social norms might foster proenvironmental behavior.

\section{WHAT ARE SOCIAL NORMS?}

Definitions of social norms vary across disciplines (Nyborg, 2018). However, most agree that they are "standards of behavior that are based on widely shared beliefs as to how individual group members ought to behave in a given situation" (Fehr and Fischbacher, 2004, p. 185). Social norms take many forms, including recurrent patterns of behavior and formalized rule-sets (Morris et al., 2015). Bicchieri (2017) argues that subjective social norms, (i.e. the perceived social pressure to participate or not in a behavior) have two components: an empirical expectation about how others do behave and a shared belief in how others should behave (Figure 1); we focus on the former.

Social norms underpin social cohesion (Bernhard et al., 2006). At the individual level, social norms emerge from a combination of imitation as a primary form of learning, our desire to belong to a social group that approves of our behavior, and the mostly predictable response by an individual to group approval or disapproval (Harré, 2018). Why do groups of individuals adhere to social norms? Among the many explanations proposed, Morris et al. (2015) identify three reasons: 1) the repeated expression of personal beliefs; 2) the desire for social acceptance and cohesion; and 3) rational decisions about interactions.

Gifford (2011) considered perceived social disapproval to be a potential barrier to adopting pro-environmental behaviors (they consider climate change). While it may be more palatable to focus on rewarding "good behaviors," sanctioning "inappropriate behaviors" is vital for the persistence and maintenance of norms (Fehr and Fischbacher, 2004; Fehr and Schurtenberger, 2018). The asymmetries between people's willingness to approve of pro-environmental behavior but unwillingness to disapprove of environmentally damaging behavior may inhibit changes to social norms. Therefore, these asymmetries can create an internal conflict between the desire for action $v s$. the desire for social acceptance (Clayton et al., 2013). A rational choice model suggests that the benefits of social inclusion should match the cost of adopting a new norm, (e.g. the cost of changing a behavior plus the cost of applying altruistic punishment to others; Ostrom, 2000). Kinzig et al. (2013, p. 171) argue that cooperative strategies for collective action problems are most likely “... with repeated interactions in smaller, more homogeneous communities ... that use punishment and communication to enforce norms". In short, cooperation is most likely where individuals have a strong awareness of each other's behavior.

\section{ALIGNMENT BETWEEN SOCIAL NORMS AND ECOLOGICAL SYSTEMS}

To evaluate whether conditions fostering pro-environmental social norms align with the features of environmental systems, we start by outlining the key conditions that determine when social norms emerge or change, drawing on the broad reasons for adherence to social norms identified by Morris et al. (2015). Recalling that our enquiry focuses on the domain of expectations about how people do behave instead of shared beliefs about how they should behave, our review of the literature has a decidedly behavioral flavor-meaning we focus on decisions more than values themselves. 


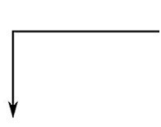

People prefer to follow it irrespective of what others do

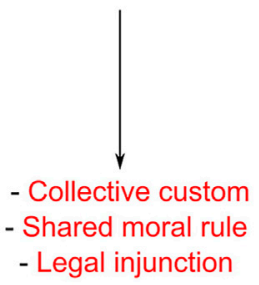

Observed collective

pattern of behaviour

People prefer to follow it

if they have social

expectations

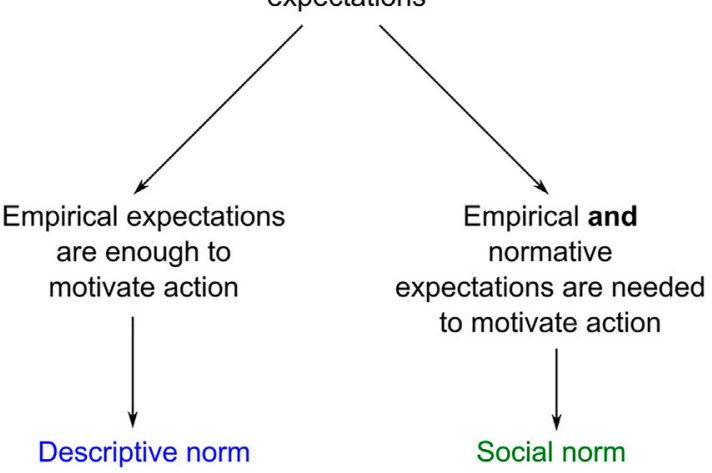

FIGURE 1 | A decision tree to evaluate what sort of norm an observed behavior relates to; adapted from Biccheri. (2017).

\section{Certainty}

Hine and Gifford. (1996) describe two uncertainties relevant to environmental decision-making: social (what will others do?) and contextual (in what setting am I making the decision?). Humans prefer to make decisions and act in contexts where the risks are known (ambiguity aversion) (Ellsberg, 1961), and uncertainty lowers the adoption of pro-environmental actions (Milfont, 2010; Gifford, 2011; Barrett and Dannenberg, 2013). As uncertainty increases, so does psychological distance, (i.e. the cognitive distance between oneself and others or events), making desirable behaviors less likely. In short, humans are much less likely to act if it is unclear that we really need to.

\section{Tangibility and Immediacy of Rewards}

Ambiguous, diffuse, or future benefits all undermine the likelihood of adopting a behavior (the intergenerational tragedy of the commons; Hauser et al., 2014) as they increase psychological distance. Conversely, vague, ambiguous, or distant rewards might widen the gap between values and actions, (e.g. "I know I should walk to work, but driving is so much quicker and easier.") (Kollmuss and Agyeman, 2002).

\section{Context}

Social norms are tied to locations and the people who inhabit them, (e.g. immediate environment, national identity, cultural identity); in short, social norms are place-bound and contextdependent. Therefore, fostering and promoting social norms usually necessitates localized, bottom-up approaches. Repeated interactions with or within a group are essential to establish rules, form a social contract, copy behaviors, receive approval, and experience disapproval. Social norms are difficult to foster between strangers and where knowledge of the likely behaviors of those being interacted with is limited (Duffy et al., 2013). This outcome is essential for pro-environmental social norms because, at large scales, individual or group decisions may be effectively anonymous.

\section{Fairness}

Fairness is a core tenet of human moral reasoning (Harré, 2018) and fosters participation by creating equality, providing clarity around reward and sanction, and encouraging widespread buyin. For example, Gowdy (2008) illustrates how conceptions of fairness are central to developing climate change policy. Equally, aversion to inequity can foster pro-social behavior by promoting actions perceived as increasing equity (Midler et al., 2015). However, a fundamental difficulty is that this judgment of fairness requires us to compare an action today, with an action in the future; such present-future comparisons are difficult, especially if we perceive a risk of others cheating (Hauser et al., 2014).

\section{Signaling/Visibility of Activities}

Signaling is an essential component of social norms (Griskevicius et al., 2010). As Young (2015) notes, the importance of a signaling behavior might not be the action itself, but its reputational value. Thus, the visibility of an action or behavior is likely an important component of social norms (Nyborg et al., 2016). While some environmental behaviors are visible, (e.g. recycling), others are not, (e.g. the decision not to travel), which makes them challenging to foster as norms; many potentially desirable pro-environmental behaviors will involve the latter.

\section{SOCIAL NORMS IN THE FACE OF UNCERTAINTY AND COMPLEX DYNAMICS}

The complexity of ecological systems is a dominant theme of environmental research and management (Christensen et al., 1996). This complexity challenges behavioral change because humans 

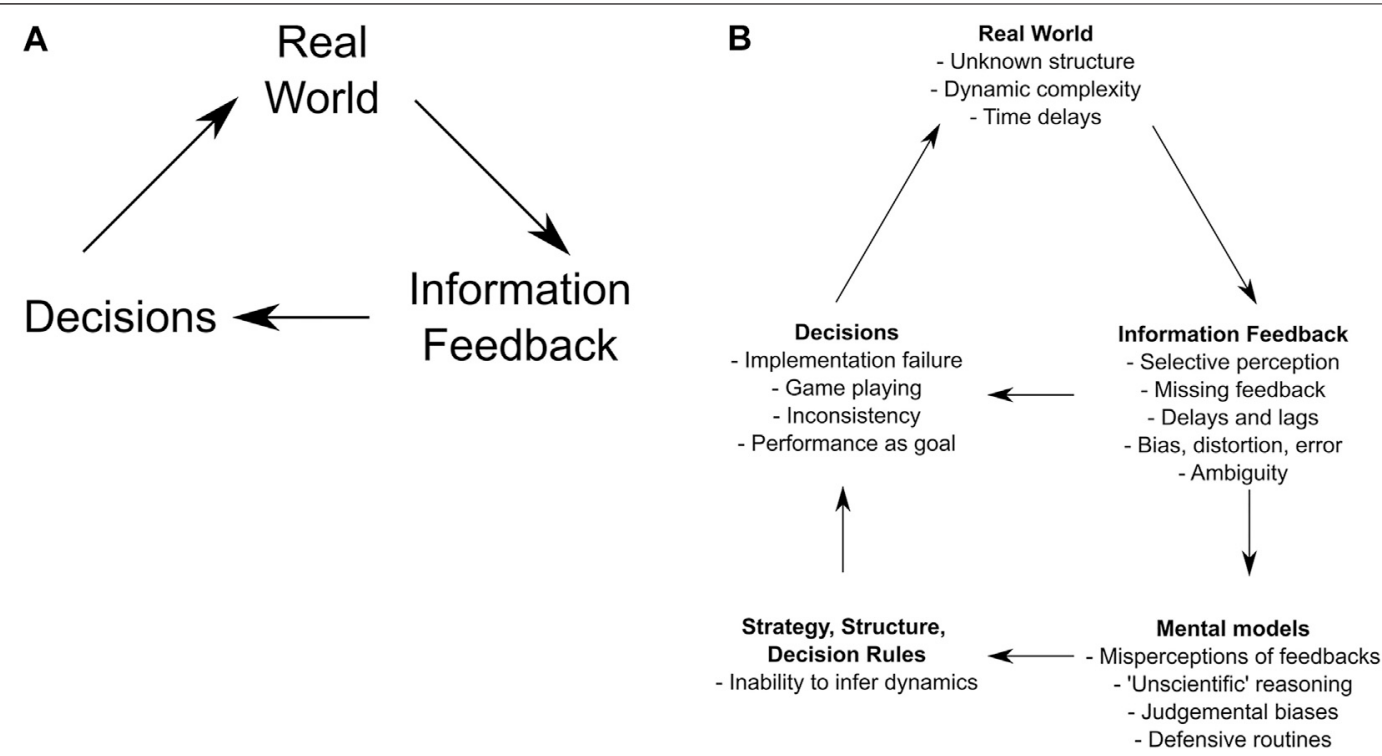

FIGURE 2 | A schematic overview of knowledge-action loops adapted from Sterman. (1994) showing (A) a simple model of decision-information flow and (B) examples of the individual and group-level uncertainties and behaviors that influence knowledge uptake and behavioral change (points below the bolded text). These multi-level uncertainties and behaviors influence the conditions under which social norms can be fostered by influencing individual decisions and hence social approval and sanctioning. These uncertainties are variously irreducible, reducible and exploitable. Figure adapted wth permission from John Wiley and Sons.

struggle to conceptualize and predict the dynamics of even the simplest systems where feedbacks are at play (Sterman, 1994; Figure 2). Amplifying this problem is that complex or open systems can exhibit "equifinality," in which the same behaviors result in contrasting outcomes, or different behaviors result in the same outcome. Such dynamics make it challenging to forecast system responses to behavioral change, or even distinguish cause from effect. Forrester (1971) argues that humans often assume that cause and effect are local system properties and tend to underestimate linkages that are more distant in time or space. Such perceptual challenges arise in engineered systems, and are more acute for environmental problems, (e.g. ocean acidification) where there are weak, spatio-temporally disjointed, shared (and often disowned) positions of responsibility (see also Pawlik, 1991; Rands et al., 2010). Uncertainty can arise in decision-making about proenvironmental behaviors as humans may receive deliberately confused messages, (i.e. misinformation) about the benefits and outcomes of their environmental behaviors (Bavel et al., 2020). These characteristics all act to increase psychological distance. In short, in this context it is extremely difficult for an individual or group to estimate the outcomes, or costs and benefits, of a given environmental action. This difficulty suggests that the psychological mechanism that might embed individual pro-environmental behaviors as collective social norms is indirect at best (Kollmuss and Agyeman, 2002).

Linking individual behaviors to ecological impacts is further obstructed by difficulties in quantifying environmental change and impacts, especially given that an action's social reward might not mirror its environmental benefit. Quantifying environmental condition and performance is complex and widely debated. There is an extensive technical discussion regarding the merits of a vast array of environmental metrics and indicators (O'Brien et al., 2016; Hillebrand et al., 2018). In the context of social norms, the question is whether these metrics provide an appropriate way to measure the outcomes of an individual's actions. The answer is, of course, "it depends."

Some components of ecological systems can be described with metrics, (e.g. physico-chemical measures) and appropriate environmental limits put in place, (e.g. relating to public health outcomes), even if this process can become worryingly politicized (Joy and Canning, 2020). For other facets of ecosystems, such as biodiversity, metrics are contextdependent, (e.g. increase in species richness is not uniformly positive) and tenuously linked to system condition, (e.g. weed and pest species' impacts are wide-ranging; Mack et al., 2000). Even if biodiversity can be measured, the numbers are not value-free (Stone, 2002). For example, individual and group perception of a species' value is often biased toward charismatic taxa, (e.g. pandas vs nematodes; Colléony et al., 2017).

One proposed solution that attempts to bridge the gap between social norms and metrics to measure ecological systems is to recognize and place economic and cultural value on the "ecosystem services" and benefits that arise from ecological entities and functions (Daily, 1997). Some argue that applying an ecosystem services approach can help foster pro-environmental behavior as the need to sustainably manage resources will become more apparent when the contribution of natural capital to the production of goods and services (including cultural and social values) from the environment is accounted for. The actual cost of producing goods from the environment needs to be tallied rather than externalized (c.f. subsidizing profit by under-pricing, and over-extracting, natural resources); such cost accounting might 
increase fairness, (e.g. the costs of soil erosion and water quality would be included in food pricing). If the internalizing of environmental costs drove behavioral change, this change might embed itself as a social norm, reinforcing the behavior itself.

The complexity of environmental systems causes three challenges for behavioral change because it is difficult for an individual to discern: 1) whether a given action (which carries some cost) will have the desired environmental effect; 2) whether there will be an associated social reward; and 3) the magnitude of that reward. The combination of these three factors risks making the individual feel powerless in the face of a large and amorphous problem like climate change. Powerlessness (or lack of selfefficacy) makes it easier for an individual to justify deciding against pro-environmental behavior despite strong proenvironmental values.

\section{IS THERE A PLACE FOR SOCIAL NORMS IN ENHANCING PRO-ENVIRONMENTAL BEHAVIOUR; AND IF SO, WHAT IS IT?}

Yes, but it is limited and concentrated in the realm of norms we focus on in this paper-expectations about how people do behave, not beliefs about how they should. As such, social norms have a place in decisions about individual behavior, and it is on this decision-making that we focus. Griskevicius et al. (2010) identify two models of motivation for environmental behavior: environmental concern and rational economics. The first emphasizes that the decision to act in a pro-environmental manner arises from some inherent concern for the environment. In contrast, the second suggests proenvironmental actions are based on economic maximization. Ultimately, this spectrum perhaps reduces to the question of the role of intrinsic (concern for the environment per se) $v s$. extrinsic, (e.g. material) motivations in adopting particular behaviors (Bénabou and Tirole, 2003).

Social norms arise from a need for personal approval, a propensity to imitation, and sanctioning; hence they are, to some degree, internally motivated. In terms of promoting persistent behaviors, this difference between intrinsic and extrinsic motivation matters for two reasons. First, there is a body of psychological evidence suggesting that the use of extrinsic incentives may detract from intrinsic motivation (Deci et al., 1999; Bénabou and Tirole, 2003) and, more specifically, social norms (Pellerano et al., 2017). At best, we might expect that extrinsically motivated social norms are less intense and less likely to endure than more intrinsically motivated ones. Second, given that social expectations underpin social norms, norms themselves are dynamic (Bicchieri, 2017).

We argue that the nature of environmental systems makes it difficult for individuals to estimate the costs and benefits of specific decisions, which is an essential component of rational choice models. Ecosystem service frameworks have a role to play by helping individuals understand the value (monetary or otherwise) of ecosystems (Daily et al., 2000). Furthermore, there is theoretical and empirical evidence that social norms play an important role in cooperative decision making about the environment. For example, Byerly et al. (2018) suggest that "nudging" (or making good behavior easier, using positive reinforcement, and making indirect suggestions) can motivate pro-environmental behaviors around energy use, recycling and other actions (Thaler and Sunstein, 2009). In many cases, these are settings where there is a direct benefit to the participant, and the norms tend to be approval-based.

Given that engrained social norms do support proenvironmental behaviors (Farrow et al., 2017; Byerly et al., 2018), an obvious question is how and where to try to use them for environmental or social benefit. According to Clayton et al. (2013), such efforts require identifying desired behaviors and their determinants. We argue that social norms are likely to be most useful for local-scale problems and where there are immediate and tangible rewards. Care must also be taken to avoid perverse and unanticipated outcomes. For example, Schultz et al. (2007) demonstrate that providing normative information influences behaviors on either side of the norm. In particular, they highlight the risk of "boomerang effects" where individuals are released from fear of sanctioning (they describe this outcome when discussing alcohol consumption, when those who discover that they consume less than the norm may feel permitted to increase their consumption). Likewise, efforts to foster social norms must acknowledge their interdependent and multi-level nature; that is, approval and sanctioning occur at multiple social levels from the individual to the community (Bicchieri, 2017).

Ultimately, environmental issues require multiple solutions (Otto et al., 2020). Social norms do contribute to the maintenance and change of behavior; however, as we have argued, the potential for using norms to change behavior is likely restricted to specific problems where the rewards of certain behaviors are tangible and outweigh the benefits of not doing it. Many of our environmental issues are spatially diffuse and play out over extended time-frames, which increases our psychological distance from them. In such settings, norms may be less effective. One solution is to reframe what are perceived as global and diffuse issues as local problems that individuals can help to solve; this is not a new idea, it is the essence of the "think global, act local" approach.

\section{CONCLUSION}

If policymakers seek to engineer new, or foster existing, proenvironmental social norms, careful consideration must be given to assessing norms' effectiveness in specific contexts (social, cultural and ecological). Unfortunately, empirical demonstration of the success of social norms is often lacking, in part because behavioral changes are typically engineered through a mixed-policy response (including regulatory and non-regulatory responses, education, and financial incentives); and government agencies rarely analyze how these policy responses interact. Thus the singular effect of norms is near impossible to assess. Such understanding could improve norms' influence on behavior. Identifying the characteristics of 
pro-environmental behavioral initiatives that 'stick', compared to those that ultimately fail, would be a valuable step. A stronger focus on the robust evaluation of the contribution of social norms to pro-environmental behaviors and decision-making could guide the development and success of more enduring proenvironmental initiatives.

\section{DATA AVAILABILITY STATEMENT}

The original contributions presented in the study are included in the article/Supplementary Material, further inquiries can be directed to the corresponding author.

\section{REFERENCES}

Barrett, S., and Dannenberg, A. (2013). Sensitivity of Collective Action to Uncertainty about Climate Tipping Points. Nat. Clim Change. 4, 36-39. doi:10.1038/nclimate2059

Bavel, J. J. V., Baicker, K., Boggio, P. S., Capraro, V., Cichocka, A., Cikara, M., et al. (2020). Using Social and Behavioural Science to Support COVID-19 Pandemic Response. Nat. Hum. Behav. 4, 460-471. doi:10.1038/s41562-020-0884-z

Bénabou, R., and Tirole, J. (2003). Intrinsic and Extrinsic Motivation. Rev. Econ. Stud. 70, 489-520. doi:10.1111/1467-937X.00253

Bernhard, H., Fischbacher, U., and Fehr, E. (2006). Parochial Altruism in Humans. Nature 442, 912-915. doi:10.1038/nature04981

Bicchieri, C. (2017). Norms in the Wild: How to Diagnose, Measure, and Change Social Norms. New York, NY: Oxford University Press. doi:10.1093/acprof:oso/ 9780190622046.001.0001

Bodin, Ö. (2017). Collaborative Environmental Governance: Achieving Collective Action in Social-Ecological Systems. Science 357, ean1114. doi:10.1126/science.aan1114

Byerly, H., Balmford, A., Ferraro, P. J., Hammond Wagner, C., Palchak, E., Polasky, S., et al. (2018). Nudging Pro-environmental Behavior: Evidence and Opportunities. Front. Ecol. Environ. 16, 159-168. doi:10.1002/fee.1777

Centola, D., Becker, J., Brackbill, D., and Baronchelli, A. (2018). Experimental Evidence for Tipping Points in Social Convention. Science 360, 1116-1119. doi:10.1126/science.aas8827

Christensen, N. L., Bartuska, A. M., Brown, J. H., Carpenter, S., D’Antonio, C., Francis, R., et al. (1996). The Report of the Ecological Society of America Committee on the Scientific Basis for Ecosystem Management. Ecol. Appl. 6, 665-691. doi:10.2307/2269460

Clayton, S., Litchfield, C., and Geller, E. S. (2013). Psychological Science, Conservation, and Environmental Sustainability. Front. Ecol. Environ. 11, 377-382. doi:10.1890/120351

Colléony, A., Clayton, S., Couvet, D., Saint Jalme, M., and Prévot, A.-C. (2017). Human Preferences for Species Conservation: Animal Charisma Trumps Endangered Status. Biol. Conservation. 206, 263-269. doi:10.1016/j.biocon.2016.11.035

Cook, C. N., Mascia, M. B., Schwartz, M. W., Possingham, H. P., and Fuller, R. A. (2013). Achieving Conservation Science that Bridges the Knowledge-Action Boundary. Conservation Biol. 27, 669-678. doi:10.1111/cobi.12050

Daily, G. C., Söderqvist, T., Aniyar, S., Arrow, K., Dasgupta, P., Ehrlich, P. R., et al. (2000). ECOLOGY: The Value of Nature and the Nature of Value. Science 289, 395-396. doi:10.1126/science.289.5478.395

Deci, E. L., Koestner, R., and Ryan, R. M. (1999). A Meta-Analytic Review of Experiments Examining the Effects of Extrinsic Rewards on Intrinsic Motivation. Psychol. Bull. 125, 627-668. doi:10.1037/0033-2909.125.6.627

Díaz, S., Settele, J., Brondízio, E. S., Ngo, H. T., Agard, J., Arneth, A., et al. (2019). Pervasive Human-Driven Decline of Life on Earth Points to the Need for Transformative Change. Science 366, eaax3100. doi:10.1126/science. aax 3100

Duffy, J., Xie, H., and Lee, Y.-J. (2013). Social Norms, Information, and Trust Among Strangers: Theory and Evidence. Econ. Theor. 52, 669-708. doi:10.1007/ s00199-011-0659-x

\section{AUTHOR CONTRIBUTIONS}

This perspective results from a workshop that all authors attended and contributed substantially to. GP and SR led writing of the manuscript and all co-authors contributed materially to writing and revision of drafts.

\section{ACKNOWLEDGMENTS}

We acknowledge funding from the Biological Heritage National Science Challenge (Project 3.1) administered by the New Zealand Ministry for Business, Innovation and the Environment.

Duit, A. (2010). Patterns of Environmental Collective Action: Some CrossNational Findings. Polit. Stud. 59, 900-920. doi:10.1111/j.1467-9248.2010. 00858.x

Ellsberg, D. (1961). Risk, Ambiguity, and the Savage Axioms. Q. J. Econ. 75, 643. doi: $10.2307 / 1884324$

Enquist, C. A., Jackson, S. T., Garfin, G. M., Davis, F. W., Gerber, L. R., Littell, J. A., et al. (2017). Foundations of Translational Ecology. Front. Ecol. Environ. 15, 541-550. doi:10.1002/fee.1733

Farrow, K., Grolleau, G., and Ibanez, L. (2017). Social Norms and Proenvironmental Behavior: a Review of the Evidence. Ecol. Econ. 140, 1-13. doi:10.1016/j.ecolecon.2017.04.017

Fehr, E., and Fischbacher, U. (2004). Social Norms and Human Cooperation. Trends Cogn. Sci. 8, 185-190. doi:10.1016/j.tics.2004.02.007

Fehr, E., and Schurtenberger, I. (2018). Normative Foundations of Human Cooperation. Nat. Hum. Behav. 2, 458-468. doi:10.1038/s41562-018-0385-5

Forrester, J. W. (1971). Counterintuitive Behavior of Social Systems. Theor. Decis. 2, 109-140. doi:10.1007/BF00148991

G. C. Daily (1997). Nature's Services: Societal Dependence on Natural Ecosystems (Washington, DC: Island Press).

Gifford, R. (2011). The Dragons of Inaction: Psychological Barriers that Limit Climate Change Mitigation and Adaptation. Am. Psychol. 66, 290-302. doi:10. $1037 / \mathrm{a} 0023566$

Gowdy, J. M. (2008). Behavioral Economics and Climate Change Policy. J. Econ. Behav. Organ. 68, 632-644. doi:10.1016/j.jebo.2008.06.011

Griskevicius, V., Tybur, J. M., and Van den Bergh, B. (2010). Going Green to Be Seen: Status, Reputation, and Conspicuous Conservation. J. Personal. Soc. Psychol. 98, 392-404. doi:10.1037/a0017346

Hardin, G. (1968). The Tragedy of the Commons. The Population Problem Has No Technical Solution; it Requires a Fundamental Extension in Morality. Science 162, 1243-1248. doi:10.1126/science.162.3859.1243

Harré, N. (2018). Psychology for a Better World: Working with People to Save the Planet. Auckland, N.Z.: Auckland University Press.

Hauser, O. P., Rand, D. G., Peysakhovich, A., and Nowak, M. A. (2014). Cooperating with the Future. Nature 511, 220-223. doi:10.1038/nature13530

Hillebrand, H., Blasius, B., Borer, E. T., Chase, J. M., Downing, J. A., Eriksson, B. K., et al. (2018). Biodiversity Change Is Uncoupled from Species Richness Trends: Consequences for Conservation and Monitoring. J. Appl. Ecol. 55, 169-184. doi:10.1111/1365-2664.12959

Hine, D. W., and Gifford, R. (1996). Individual Restraint and Group Efficiency in Commons Dilemmas: The Effects of Two Types of Environmental Uncertainty1. J. Appl. Soc. Pyschol. 26, 993-1009. doi:10.1111/j.1559-1816.1996.tb01121.x

Joy, M. K., and Canning, A. D. (2020). Shifting Baselines and Political Expediency in New Zealand. Mar. Freshw. Res. 72 (4), 456-461. doi:10.1071/MF20210

Kinzig, A. P., Ehrlich, P. R., Alston, L. J., Arrow, K., Barrett, S., Buchman, T. G., et al. (2013). Social Norms and Global Environmental Challenges: the Complex Interaction of Behaviors, Values, and Policy. BioScience 63, 164-175. doi:10. 1525/bio.2013.63.3.5

Kollmuss, A., and Agyeman, J. (2002). Mind the Gap: Why Do People Act Environmentally and what Are the Barriers to Pro-environmental Behavior? Environ. Edu. Res. 8, 239-260. doi:10.1080/13504620220145401 
Mack, R. N., Simberloff, D., Mark Lonsdale, W., Evans, H., Clout, M., and Bazzaz, F. A. (2000). Biotic Invasions: Causes, Epidemiology, Global Consequences, and Control. Ecol. Appl. 10, 689-710. doi:10.1890/1051-0761(2000)010[0689: BICEGC]2.0.CO;2

Midler, E., Pascual, U., Drucker, A. G., Narloch, U., and Soto, J. L. (2015). Unraveling the Effects of Payments for Ecosystem Services on Motivations for Collective Action. Ecol. Econ. 120, 394-405. doi:10.1016/j.ecolecon.2015.04.006

Milfont, T. (2010). "Global Warming, Climate Change and Human Psychology," in Psychological Approaches To Sustainability: Current Trends In Theory, Research And Applications. Editors V. Corral-Verdugo, C. H. Garcia-Cadena, and M. Frias-Armenta (New York: Nova Science Publishers, Inc.).

Morris, M. W., Hong, Y.-Y., Chiu, C.-Y., and Liu, Z. (2015). Normology: Integrating Insights about Social Norms to Understand Cultural Dynamics. Organizational Behav. Hum. Decis. Process. 129, 1-13. doi:10.1016/j.obhdp. 2015.03.001

Nyborg, K., Anderies, J. M., Dannenberg, A., Lindahl, T., Schill, C., Schluter, M., et al. (2016). Social Norms as Solutions. Science 354, 42-43. doi:10.1126/science. aaf8317

Nyborg, K. (2018). Social Norms and the Environment. Annu. Rev. Resour. Econ. 10, 405-423. doi:10.1146/annurev-resource-100517-023232

O’Brien, A., Townsend, K., Hale, R., Sharley, D., and Pettigrove, V. (2016). How Is Ecosystem Health Defined and Measured? A Critical Review of Freshwater and Estuarine Studies. Ecol. Indicators. 69, 722-729. doi:10.1016/j.ecolind.2016. 05.004

Ostrom, E. (2000). Collective Action and the Evolution of Social Norms. J. Econ. Perspect. 14, 137-158. doi:10.1257/jep.14.3.137

Otto, I. M., Donges, J. F., Cremades, R., Bhowmik, A., Hewitt, R. J., Lucht, W., et al. (2020). Social Tipping Dynamics for Stabilizing Earth's Climate by 2050. Proc. Natl. Acad. Sci. USA. 117, 2354-2365. doi:10.1073/pnas.1900577117

Oullier, O. (2013). Behavioural Insights Are Vital to Policy-Making. Nature 501, 463. doi:10.1038/501463a

Pawlik, K. (1991). The Psychology of Global Environmental Change: Some Basic Data and an Agenda for Cooperative International Research. Int. J. Psychol. 26, 547-563. doi:10.1080/00207599108247143

Pellerano, J. A., Price, M. K., Puller, S. L., and Sánchez, G. E. (2017). Do extrinsic Incentives Undermine Social Norms? Evidence from a Field Experiment in
Energy Conservation. Environ. Resource Econ. 67, 413-428. doi:10.1007/ s10640-016-0094-3

Rands, M. R. W., Adams, W. M., Bennun, L., Butchart, S. H. M., Clements, A., Coomes, D., et al. (2010). Biodiversity Conservation: Challenges beyond 2010. Science 329, 1298-1303. doi:10.1126/science.1189138

Ripple, W. J., Wolf, C., Newsome, T. M., Galetti, M., Alamgir, M., Crist, E., et al. (2017). World Scientists' Warning to Humanity: A Second Notice. BioScience 67, 1026-1028. doi:10.1093/biosci/bix125

Schultz, P. W., Nolan, J. M., Cialdini, R. B., Goldstein, N. J., and Griskevicius, V. (2007). The Constructive, Destructive, and Reconstructive Power of Social Norms. Psychol. Sci. 18, 429-434. doi:10.1111/j.1467-9280.2007. 01917.x

Sterman, J. D. (1994). Learning in and about Complex Systems. Syst. Dyn. Rev. 10, 291-330. doi:10.1002/sdr.4260100214

Stone, D. A. (2002). Policy Paradox: The Art of Political Decision Making. Rev. ed. New York: Norton.

Thaler, R. H., and Sunstein, C. R. (2009). Nudge: Improving Decisions About Health, Wealth, and Happiness, Rev. and expanded ed. New York, NY: Penguin Books.

Young, H. P. (2015). The Evolution of Social Norms. Annu. Rev. Econ. 7, 359-387. doi:10.1146/annurev-economics-080614-115322

Conflict of Interest: Author DH was employed by company DairyNZ. Author FM was employed by company The Catalyst Group.

The remaining authors declare that the research was conducted in the absence of any commercial or financial relationships that could be construed as a potential conflict of interest.

Copyright (C) 2021 Perry, Richardson, Harré, Hodges, Lyver, Maseyk, Taylor, Todd, Tylianakis, Yletyinen and Brower. This is an open-access article distributed under the terms of the Creative Commons Attribution License (CC BY). The use, distribution or reproduction in other forums is permitted, provided the original author(s) and the copyright owner(s) are credited and that the original publication in this journal is cited, in accordance with accepted academic practice. No use, distribution or reproduction is permitted which does not comply with these terms. 